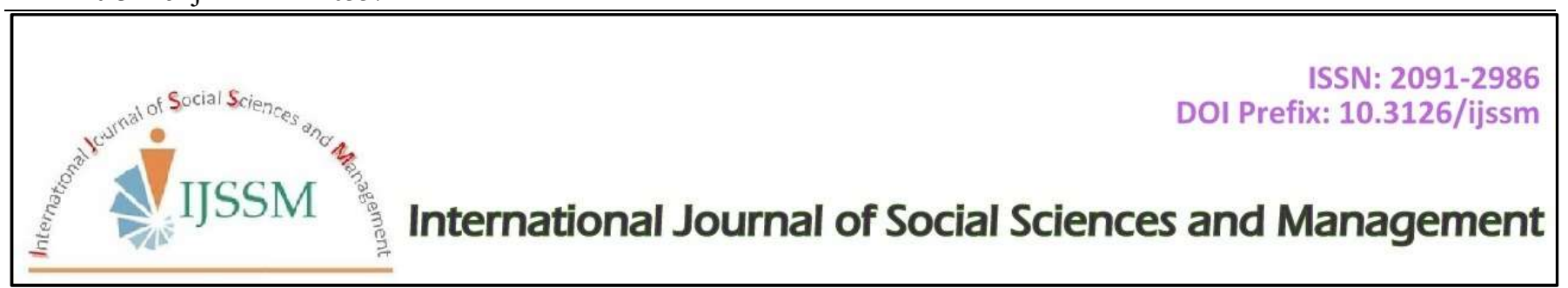

Mini Review

\title{
Integrating Classical Language to Modern Media Platforms: A Multimodal Approach towards Mainstreaming Sanskrit
}

\author{
S.M.Alfarid Hussain and Neelatphal Chanda \\ Department of Mass Communication,Assam University, Silchar, Assam 788011, India \\ Corresponding author's email: neelatphalchanda48@gmail.com
}

\begin{abstract}
This ancient language, considered to be the mother language of a majority of Indian languages, today appears to be fighting a losing battle with only about 14,000 people in India claiming Sanskrit as their mother tongue in a country of over 1.2 billion people, as the 2011 census data reveal. In an era increasingly engulfed by the forces of globalization amidst the debates surrounding linguistic homogenization and cultural neo-imperialism, mass media as well as various digital media platforms, including social media can contribute towards restoring the rich literary tradition of the Sanskrit language that defines the very essence of what we understand as 'Indian culture.' This paper argues that state-run public service broadcasters like Doordarshan and All India Radio, are obligated to create and transmit content that generate awareness about Sanskrit and its significance to modern Indian knowledge like Ayurveda, yoga, music, grammar, philosophy, Vedic mathematics etc. Yet, this paper argues that the public broadcasters should be careful not to create an arcane and pedantic programming structure meant exclusively for a select oligarchy of Sanskrit specialists, but should rather embark on creative programming formats that would actually attract the young people towards learning the language and understanding its relevance. The social media ecosystem reflects the continued dominance of English as a mode of communication, which implies the complex hegemonic processes that are at work. Yet, there is a growing population of people engaging in social media in their own respective languages. This paper argues that the egalitarian nature of social media coupled with the horizontal type of user-generated content flow architecture provides the perfect spawning ground for the preservation and promotion of Sanskrit in the 21st century society.
\end{abstract}

Keywords:Hegemony; Linguistic homogenization; Mass Media; Sanskrit; Social Media.

\section{Sanskrit:Mere language or Way of Life?}

Sanskrit is not just a language but also an inexhaustible treasure of knowledge. The roots of many languages are found in Sanskrit, which some call the mother of all languages, distinguished from the rest by its longevity, stability of form over the many millennia, and accorded the status of a sacred language.

"One of ancient India's greatest achievements is her remarkable alphabet, commencing with the vowels and followed by the consonants, all classified very scientifically according to their mode of production, in sharp contrast to the haphazard and inadequate Roman alphabet, which has developed organically for three millennia. It was only on the discovery of Sanskrit by the
West that a science of phonetics arose in Europe." (Basham and Rizvi, 1956).

Sanskrit remained the most fertilelanguage during the Twentieth Century. It is considered as the treasure house of modern Indian knowledge like Ayurveda, yoga, music, grammar, philosophy, astronomy, Vedic mathematics etc. Sanskrit writers kept theirrelation with ancient traditions, forms, culture and beauty of originality.They also reflected the order and disorder of democracy, everchangingpolitical, social and economic environment, the suffocation of modernlife and reactions towards worldaffecting events and incidents.

There has been an outstanding discovery made at the NASA research center in the eighties. It was discovered 
that Sanskrit, the world's oldest spiritual language, is the only unambiguous spoken language on the planet. Rick Briggs' work demonstrates that Sanskrit can serve as an artificial intelligence also.

"In the past twenty years, much time, effort, and money has been expended on designing an unambiguous representation of natural languages to make them accessible to computer processing. These efforts have centered on creating schemata designed to parallel logical relations with relations expressed by the syntax and semantics of natural languages, which are clearly cumbersome and ambiguous in their function as vehicles for the transmission of logical data. Understandably, there is a widespread belief that natural languages are unsuitable for the transmission of many ideas that artificial languages can render with great precision and mathematical rigor". (Briggs, 1985)

Issues such as patriotism, social consciousness, Gandhian thoughts, communism, the sensibility of new-age feminism, and the contradictions of modern-day existence were experienced and expressed in Sanskrit during the twentieth century.However, in Independent India,although Sanskrit has been listed as one among the 22 official languages under the Eighth Schedule of the Constitution, it has fallen into hard times.According to the 2011 Census data, a mere 14,135 people have claimed Sanskrit as their mother tongue. This language has the lowest number of speakers among all the 22 official languages of the country. Recently, in an attempt to revitalize the language, Uttarakhand has declared Sanskrit language as 'other officially recognized languages' in the state, the only state in the country to do so.

\section{Sanskrit in a Post-Globalized World}

As the world becomes increasinglyglobalizedpropelling human civilization to the threshold of a networked society, it is seen that language diversity is plummeting at an unprecedented rate. The homogenizing effect of globalization has resulted in the emergence of a marketladen monoculture ruthlessly swallowing the heterogeneity and diversity of cultures, and posing a grave threat to the existence of various languages.

Linguists like Lenore Grenoble of the University of Chicago have suggested the impact of global economies on language diversity for years. It is an argument that goes all the way back to the 1970s, when Herbert Schiller proposed the hotly debated theory of cultural imperialism, which suggested that economically powerful nations hold immense cultural sway over the weaker countries they infiltrate. According to UNESCO,

'Languages are threatened by external forces such as military, economic, religious, cultural or educational subjugation, or by internal forces such as a community's negative attitude towards its own language.'

As economic power grows, the argument goes, so do opportunities to leverage that influence in order to bend cultural institutions to the will of the dominant group. Language, indeed, is a particularly salient domain of culture that appears to be intimately tied to economic power. Joseph Nye's idea of soft power-defined as the ability of a powerful nation to 'set the rules of the game' for a weaker one, culturally and economically speaking.

Two different theories have been constructed concerning the role English plays as a world language. As per the exploitation theory it acts in an imperialistic manner or if we are going with grass roots theory it takes on a neutral role in enabling cross-border communication.

Whenever we use the term 'globalization' we are positioning ourselves in the West/Rest discourse and implicit western superiority. In contemporary global culture, the prime issues are who owns the means of communication. "The very language we use to describe the so-called facts interferes in this process of finally deciding what is true and what is false". (Hall, 1996)

Robert Phillipson too, in his book Linguistic Imperialism speaks about the complex hegemonic processes which, he asserts, continues to sustain the pre-eminence of English in the world today. He contends that the species of prejudice that leads to endangered languages becoming extinct or losing their local eminence is due to the rise and competing prominence of English.

\section{Mixed Media Approach for the Preservation and Sustenance of Sanskrit}

There is an urgent need to sustain the currency of Sanskrit at various levels, given that it is the mother language of a majority of Indian languages. Mass media, by virtue of their immense reach and influence, can play a significant role in the preservation and sustenance of this language. The massmedia should not merely be accepted as a valueneutral institution of information transmission, but rather, one should concede, that they influence the shaping of an individual's world view and frames of reference, an awareness of his or her own social and cultural realities, as well as the environment in which he or she goes about her daily social transactions.

\footnotetext{
"The mass media are important forces in our society. They provide information and entertainment and, at the same time, have persuasive powers that are capable of effecting radical changes. For this reason, the role of the mass media in the development and promotion of our culture, moral and community life cannot be overestimated". (Voelker, 1975)
} 
With the rapid changes in the media landscape in India, especially in the post-liberalization period, there is an urgent need to employ a mixed media approach for the preservation, promotion and publicity of endangered languages in the country, including Sanskrit. An essential feature of this method is the incorporation of modern tools and communication avenues and embedding them to the collective cultural consciousness of a society in transition. Traditional mass media approach is not enough to maintain the currency of Sanskrit. The modern mass media have to follow parallel processing approach given the diverse nature of the audience interested in Sanskrit. It is on the media to scatter knowledge from very basic level, to a deeper level of understanding and enjoyment and those engaging with it in a professional manner leading to research and enhancement of the state of current knowledge.In this knowledge society, the more inclination there has been to develop communication technology to its fullest potential, especially in the sense of being universally acceptable and widely used. The use of media such as TV and Radio channels, Social Networking Websites, YouTube platform, dedicated web portals and print media helps in popularization of this language.

\section{Social media and its specialized approach in the promotion of language}

Technology has done a great deal to change our communication behavior. Social media has tremendous effect on the language and how we can communicate. With the mammoth growth of globalization, there is a paradigm shift in the usage of social media. The global economies provide access to inexpensive communication technologies like the internet and mobile devices. These technologies are increasingly enlisted as tools to increase the use of languages in an egalitarian nature to develop basic resources that help people use this language online.

To popularize Sanskrit language in the platform of social media, Doordarshan (DD) has launched an exclusive page on Facebook and a Twitter handle in Sanskrit language on the eve of 'Sanskrit Diwas' celebration. This horizontal type of user-generated content flow architecture provides the perfect breeding ground for the preservation and promotion of this language. User generated content allow users to collaborate in a way that helps them creative, connect with one another, or ask and answer questions enhancing the activity of the site and the respective language.

The major challenge which social media is confronting is the continued dominance of English as a mode of communication. The problem of linguistic hegemony is crucial to the development of human and cultural security. Wiley suggested "Linguistichegemony is achieved when dominant groups create a consensus by convincing others toaccept their language norms and usage as standard or paradigmatic. Hegemony is ensuredwhen they can convince those who fail to meet those standards to view their failure as beingthe result of the inadequacy of their own language" (Wiley, 2000).

The linguistic hegemony of the English language as a global language has generated heated debates in literature. Phillipson (1992) theorize linguistic imperialism with a particular focus on the spread and use of English on the bases of historicity and politics through the British Council and specialists in the language.

The initiation of the "Information Superhighway" by the US and global spread of Internet were the breeding ground of imbalance and inequality in the flow of information and catalyzing the dominance of English on the Internet. The dominance of English is not merely creating cultural and linguistic homogenization, but it also reinforcing the structure of inequality between English and other languages.

\section{Online web forum for Sanskrit promotion}

There are dedicated online forum such as Learn Sanskrit Online, which mainly focus on various aspects of Sanskrit learning. This online forum provides learning material on basic conversations, grammar, Sanskrit numerology, audio clips and RSS feeds etc (http://www.learnsanskrit.org/).

A compilation links for Sanskrit video and audio clips for learning Sanskrit is also available in a dedicated portal of Sanskrit documents. This forum is the hub of Sanskrit Video (Lectures, Conversations, Classes, and Lessons) of learned scholars and leaders (http://sanskritdocuments.org/media).

To teach the most useful and common parts of Sanskrit grammar as early as possible dedicated portal. The guide is split into units, each of which talks about a specific chunk of Sanskrit grammar. Within these units are chapters, which focus on a particular area of Sanskrit. These chapters are split into individual lessons, which cover an aspect of that area in detail. There is dedicated website of SanskritaBharati,an organization that is promoting Sanskrit across the worldwide. The website covers courses on Sanskrit learning, blog, book storeetc. (http://learnsanskrit.org/grammar).

\section{Public Broadcaster in generalizing this language}

Public service broadcasting is a major tool in initiating informed social change in people and nations through mass media. Keeping this core approach in mind Doordarshan has launched weekly half hour News Mag in Snaskrit on Jnauary 28, 2015. The program has news, reportage, features and discussions in Sanskrit. The channel already has five minute Sanskrit news bulletin'Varta'-which is telecast at 6:55 PM every day. DD News also has its exclusive program on Sanskrit 'Vaartavali' which comes on evening prime time slot on Saturdays. 
These are all laudable efforts put forwarded by public service broadcasters like Doordarshan and All India Radio, but they are required to generate and promote the awareness level of this ancient language for general audience. They should be careful not to create an arcane and pedantic delivery structure for aselect oligarchy of Sanskrit specialists only. While TV broadcasting they may use subtitles in Hindi or in English which helps heterogeneous audience to enjoy the programming.

Prof. Sheldon Pollock from University of Chicago while referring to the death of Sanskrit mentions "The disparities between political inputs and cultural outcomes could be detailed across the board. What it all demonstrates-the Sanskrit periodicals and journals, feature films and daily newscasts on All-India Radio, school plays, prize poems and the rest- may be too to mention: that Sanskrit as a communicative medium in contemporary India is completely denaturalized. Its cultivation constitutes largely an exercise in nostalgia for those directly involved, and, for outsiders, a source of bemusement that such communication takes place at all. Government feeding tubes and oxygen tanks may try to preserve the language in a state of quasi-animation, but most observes would agree that, in some crucial way, Sanskrit is dead" (Pollock, 2001).

These are the schematic diagrams showing the possibilities in generalizing this ancient language for larger audiences along with this it also depends on the public service broadcasters to embark on creative programming formats that would actually attract the young people towards learning the language and understanding its relevance in contemporary period.

\section{Digitization of Endangered languages}

In a country of over a billion people, there are about 14,000 people who claim Sanskrit is their mother tongue, an analysis of Census numbers reveals. This figure replicates the pathetic condition of the language which is considered as the mother of all modern Indian languages. Some might argue that Sanskrit is a learned language of intellectual discourse. Scholars also assume that Sanskrit was never alive has discouraged the attempt to grasp its history (Sreevatsan, 2014).

According to estimates by the Endangered Languages Project, forty percent of the world's 7000 languages at risk of disappearing. The dominating effect of a single socio economic factor, GDP per capita, on speaker growth rate suggests that economic growth and globalization are the primary drivers of recent language speaker declines (Pearson, 2014).
While globalization is considered as a primary factor in language endangerment, global economies also provide access to modern communication technologies - and these technologies are increasingly enlisted as tools to increase the use of endangered languages. Social media services like Facebook, Twitter promote language use and language learning.

In the days of technological advancement organization and individual working hard to tackle the language endangerment by documenting, preserving and teaching them. Though the digital platform, users can not only access the most up to date and comprehensive information on endangered languages as well as they can get samples in the form of text, audio or video files. This platform helps user to share best practices and case studies related to the language promotion among the larger audiences. The tools and technology at our fingertip could become a game changer.

\section{References}

Basham AL and Rizvi SAA (1956)The Wonder That Was India. Sidgwick and Jackson.

Briggs R (1985) Knowledge Representation in Sanskrit and Artificial Intelligence. Artificial Intelligence Magazine. Volume. 6.

Hall S (1996) The West and the Rest: Discourse and power. In: HallS, HeldD, HubertD and Thompson K(Eds.) Modernity: An introduction to modern societies, Blackwell Publishing: Malden.

Pearson J(September 03, 2014) Globalization Is a Leading Factor in the Death of Minority Languages.Vice Media. Retrieved on November 15, 2016.http://motherboard.vice.com/read/globalization-isa-leading-factor-in-the-death

Phillipson R (1992)Linguistic Imperialism. Oxford University Press.

Pollock S (2001) The Death of Sanskrit. Comparatives Studies in Society and History43(02): 392-426

Sreevatsan A (August 10, 2014) Where are the Sanskrit speakers? The Hindu, Chennai, Retrieved on November 04, 2016. http://www.thehindu.com/news/national/whereare-the-sanskrit-speakers/article6299433.ece

Voelker FH (1975) Mass Media: Forces in Our Society. Harcourt College Publishing: Atlanta.

Wiley TG (2000) Language Planning and Policy. In:McKay SL and HornbergerNH (Eds.) Sociolinguistics and Language Teaching, Cambridge University Press: Cambridge. 